\title{
The Economic Crisis in Greece and Its Impact on the Seasonality of Suicides in the Athens Greater Area
}

\author{
Christos Christodoulou ${ }^{1}$, Vasiliki Efstathiou', Ioannis Michopoulos ${ }^{1}$, Maria Gkerekou', \\ Antonios Paraschakis ${ }^{2}$, Filippos Koutsaftis ${ }^{3}$, and Athanassios Douzenis ${ }^{1}$ \\ ${ }^{1}$ Second Department of Psychiatry, University of Athens Medical School, "Attikon" University General Hospital, Athens, Greece \\ ${ }^{2}$ Psychiatric Hospital of Attica "Dafni", Athens, Greece \\ ${ }^{3}$ Athens Department of Forensic Medicine, Ministry of Justice, Athens, Greece
}

\begin{abstract}
Objective The economic crisis and the implementation of austerity measures in Greece lead to significant socioeconomic changes. The effects of the crisis were mainly felt by the Greek population during the years 2011 and 2012. This study aimed to investigate the impact of Greece's economic crisis on the seasonality of suicides in the Athens Greater Area.

Methods Data were collected for all recorded cases of suicides committed over a 5-year period (from 2008 to 2012) from the Athens Department of Forensic Medicine. Two sub-periods were studied in relation to the economic crisis: 2008-2010 and 2011-2012. Seasonality was estimated with the Poison regression variant of the circular normal distribution.

Results Suicide seasonality appeared significant during 2008-2010 (relative risk, RR=1.36) and strengthened in the years 2011-2012 $(\mathrm{RR}=1.69)$, when the impact of the austerity measures was increasingly being felt by the Greek society. Regarding the latter sub-period, seasonality was established for males $(R R=1.75)$, individuals aged 45 years or more $(R R=1.75)$ and suicide by hanging $(R R=1.96)$.

Conclusion The economic crisis in Greece, especially in the period during its effects had a significant impact on the population's economic condition, seems to have strengthened the seasonality of suicides, while a noteworthy suicide risk of $96 \%$ was revealed for suicides by hanging (peak in early June).

Psychiatry Investig 2017;14(1):16-20
\end{abstract}

Key Words Suicide, Seasonality, Economic crisis.

\section{INTRODUCTION}

The seasonal variation of suicides has been well documented. ${ }^{1}$ However it appears to diminish over time and eventually to disappear, at least in countries of the Western world. ${ }^{2} \mathrm{~A}$ number of theories that attempt to explain the presence or disappearance of the phenomenon of suicide seasonality, with often contradictory conclusions, has been developed. ${ }^{1}$ Economic strain can influence suicidality both directly, by increasing poverty and unemployment, and indirectly, as the financial strain increases alcohol consumption and marital discord. ${ }^{3}$

There are relatively few studies that examine the effect of the

Received: September 29, 2015 Revised: March 12, 2016

Accepted: March 21, 2016 Available online: September 9, 2016

$\bowtie$ Correspondence: Christos Christodoulou, PhD

Second Department of Psychiatry, University of Athens Medical School, "Attikon" University General Hospital, 1 Rimini Street, 12462 Athens, Greece

Tel: +302105832426 , Fax: +302105326453

E-mail: christo.christodoulou@gmail.com

(a) This is an Open Access article distributed under the terms of the Creative Commons Attribution Non-Commercial License (http://creativecommons.org/licenses/bync/3.0) which permits unrestricted non-commercial use, distribution, and reproduction in any medium, provided the original work is properly cited. socio-economic changes in certain countries on suicide seasonality. It is generally suggested that the seasonal variation of deaths by suicide is influenced by changes in the socio-economic conditions. ${ }^{4,5}$ In Greece the seasonal variation of suicides has been well documented through the years. ${ }^{6,7}$

Although the European economic crisis started in 2008, its impact on the Greek population, in terms of unemployment increase and reduced income, has mainly appeared after 2010 when a Memorandum of economic and financial policies was signed and number of austerity measures was implemented, in order to avert Greece's default. The effects of the crisis were felt by the Greek population mainly during the years 2011 and 2012. ${ }^{8-10}$

The purpose of the current study is to investigate the possible effect of the economic crisis in Greece on the seasonal variation of suicides in the Athens Greater Area. We hypothesize that suicide seasonality should significantly diminish or even disappear due to the acute and continuous deterioration of the economic situation (in Greece there wasn't a gradual transition but an abrupt change in a relatively short time), which 
should reasonably outweigh the other factors that contribute to seasonality.

\section{METHODS}

Data were collected for all recorded cases of suicides committed over a 5-year period (January 1st, 2008 until December 31st, 2012) from the Athens Department of Forensic Medicine. Since the objective of the current research is to investigate the possible effect of the economic crisis in Greece on the seasonal variation of suicides in the Athens Greater Area, two time periods were selected and examined. The former time period was from January 1st, 2008 to December 31st, 2010, when the US banking crisis started to gradually affect the economy in Europe, but without its results being at that time felt in the Greek population. The latter period was from January 1st, 2011 to December 31st, 2012 after Greece's bailout by the international community in 2010 and the subsequent implementation of austerity measures, which lead to socio-economic changes and affected mental health. ${ }^{8}$ The Athens Department of Forensic Medicine covers an area of approximately $40 \%$ of Greece's population. Thus, the sample of our study could be considered highly representative of the total population in Greece.

Data collection and evaluation included sociodemographic parameters (age, sex) and characteristics of the suicidal act (method of suicide, date and month). The recognition of all the cases examined was based on autopsy examination, and the incorporation of data as reported to the referral for autopsy medical summaries. The research was approved by the ethics committee of Athens Department of Forensic Medicine.

Descriptive statistics were measured and presented as mean \pm standard deviation, while the significance of differenc- es was examined using independent Student's t-test. The presence of seasonality and its relationship with sex, age, and method of suicide was estimated with the Poison regression variant of the circular normal distribution. This is a method similar to the Edwards method and provides a reliable estimation of the peak month for suicide, the relative risk (RR) of committing suicide during this month, comparing it with the minimum incidence during the whole year and confidence intervals for these estimates. The method was used as modified by Frangakis and Varadhan ${ }^{11}$ while the relevant statistical analysis was carried out using R stats (R Foundation for Statistical Computing, Vienna, Austria). The remainder of the data was statistically analyzed by SPSS (Version 20.0, IBM Corp., Armonk, NY, USA). Statistical significance level was set at $\mathrm{p}<0.05$.

\section{RESULTS}

The time period 2008-2012 was divided due to the aforementioned reasons into two sub-periods; from 2008 to 2010 and from 2011 to 2012. According to the data collected from the Athens Department of Forensic Medicine, 868 completed suicides were recorded from 2008 to 2012 (705 male and 163 female suicide victims). More analytically, there were 530 completed suicides recorded from January 1st, 2008 to December 31st, 2010 (427 male and 103 female suicide victims, ratio $=4.15: 1$ ), while there were no significant differences between male (mean age, 52.16 \pm 18.73 ) and female (mean age, $55.93 \pm 18.99)$ suicide victims with regard to age $(t=-1.83$, $\mathrm{p}=0.07)$. Regarding the latter time period from January 1st, 2011 to December 31st, 2012, 338 suicides were recorded (278 male and 60 female suicide victims, ratio=4.64:1), and no significant differences were observed among male (mean age,

Table 1. Distribution of suicides by method for 2008-2010, 2011-2012, and 2008-2012

\begin{tabular}{|c|c|c|c|c|c|c|}
\hline \multirow{2}{*}{ Suicide by } & \multicolumn{2}{|c|}{$2008-2010$} & \multicolumn{2}{|c|}{$2011-2012$} & \multicolumn{2}{|c|}{$2008-2012$} \\
\hline & $\mathrm{N}$ & $\%$ & $\mathrm{~N}$ & $\%$ & $\mathrm{~N}$ & $\%$ \\
\hline Hanging & 189 & 35.66 & 130 & 38.46 & 319 & 36.75 \\
\hline Jumping & 173 & 32.64 & 125 & 36.98 & 298 & 34.33 \\
\hline Shooting & 85 & 16.04 & 61 & 18.05 & 146 & 16.82 \\
\hline Burning & 21 & 3.96 & 5 & 1.48 & 26 & 3.00 \\
\hline Cutting and piercing & 16 & 3.02 & 5 & 1.48 & 21 & 2.42 \\
\hline Drowning & 14 & 2.64 & 3 & 0.89 & 17 & 1.96 \\
\hline Chemicals & 10 & 1.89 & 3 & 0.89 & 13 & 1.5 \\
\hline Railway & 10 & 1.89 & 3 & 0.89 & 13 & 1.5 \\
\hline Drug-overdose & 6 & 1.13 & 1 & 0.29 & 7 & 0.81 \\
\hline Other & 6 & 1.13 & 2 & 0.59 & 8 & 0.92 \\
\hline All means & 530 & 100 & 338 & 100 & 868 & 100 \\
\hline
\end{tabular}


$50.96 \pm 18.57)$ and female (mean age, $48.54 \pm 18.23$ ) suicide victims with regard to age as well $(\mathrm{t}=0.91, \mathrm{p}=0.36)$. The distribution of the completed suicides by method is presented in Table 1 .

The statistical assessment of seasonality was done with the Frangakis and Varadhan method, as already mentioned. ${ }^{11}$ Regarding the overall period from 2008 to 2012, significant seasonality with a peak in June was observed, which was established mainly for men, suicide by hanging and individuals aged 45 years or more (Table 2).

As regards the period from January 1st, 2008 to December 31st, 2010, significant seasonality was observed with a peak late in the month of May, with confidence intervals April (early)-July (early), while suicide risk was increased by $36 \%$ [RR $=1.36$ (95\% confidence intervals $1.0-1.65), \mathrm{p}=0.045]$. A significant seasonality was noted for individuals aged 45 years or more $(\mathrm{p}=0.018)$ with a peak in the month of May as well (late of May) and an increased suicide risk of 56\%. It should be noted that statistically significant seasonality was not established either for sex or for any of the suicide methods (Table 2).

Concerning the period from January 1st, 2011 to December 31st, 2012, significant seasonality was established with a peak late in the month of June, with confidence intervals MayJuly (late), while suicide risk was increased by $69 \%$ [RR $=1.69$ (95\% confidence intervals 1.27-2.3), $\mathrm{p}=0.002$ ]. A significant seasonality was also observed for males in the same month ( $\mathrm{p}=0.005$ ), for whom suicide risk was increased by $75 \%$. A significant seasonality was observed for individuals aged 45 years or more $(\mathrm{p}=0.025)$ with a peak in the month of July (early of July) and an increased suicide risk of $75 \%$. Regarding the suicide methods, a significant seasonality was established for sui-

Table 2. Seasonality of suicides according to sex, age, and the method used

\begin{tabular}{|c|c|c|c|c|c|c|}
\hline Seasonality & Suicides $(\mathrm{N})$ & RR & $95 \%$ CIs & $\mathrm{p}$-value & Peak month & CIs in months \\
\hline \multicolumn{7}{|l|}{ From 2008 to 2010} \\
\hline Total & 530 & 1.36 & $1-1.65$ & $0.045^{*}$ & May & April (early)-July (early) \\
\hline Males & 427 & 1.36 & $1-1.78$ & 0.09 & May & April (early)-July \\
\hline Females & 103 & 1.32 & $1-2.28$ & 0.63 & April & January-August \\
\hline By hanging & 189 & 1.51 & $1-2.27$ & 0.14 & April (late) & March (early)-June (late) \\
\hline By jumping & 173 & 1.45 & $1-2.20$ & 0.23 & July (late) & May-October (early) \\
\hline By shooting & 85 & 1.69 & $1-3.11$ & 0.24 & May (early) & February (late)-July \\
\hline Age $<45$ & 196 & 1.18 & $1-1.76$ & 0.71 & March & January-August (early) \\
\hline Age $\geq 45$ & 332 & 1.56 & $1-2.13$ & $0.018^{*}$ & May (late) & April-July (early) \\
\hline \multicolumn{7}{|l|}{ From 2011 to 2012} \\
\hline Total & 338 & 1.69 & $1.27-2.30$ & $0.002 *$ & June (late) & May-July (late) \\
\hline Males & 278 & 1.75 & $1.25-2.45$ & $0.005^{*}$ & June (late) & May-July (late) \\
\hline Females & 60 & 1.40 & $1-2.89$ & 0.664 & July & March-November \\
\hline By shooting & 61 & 1.77 & $1-3.64$ & 0.30 & June & March (late)-August \\
\hline By hanging & 130 & 1.96 & $1.15-3.22$ & $0.03^{*}$ & June (early) & April (late)-July \\
\hline By jumping & 125 & 1.45 & $1-2.39$ & 0.34 & July (late) & May-October \\
\hline Age $<45$ & 144 & 1.62 & $1-2.59$ & 0.13 & June & April (late)-August \\
\hline Age $\geq 45$ & 193 & 1.75 & $1.15-2.63$ & $0.025^{*}$ & July (early) & May-August \\
\hline \multicolumn{7}{|l|}{ From 2008 to 2012} \\
\hline Total & 868 & 1.45 & $1.20-1.69$ & $<0.001^{*}$ & June & May-July (early) \\
\hline Males & 705 & 1.47 & $1.19-1.82$ & $0.001^{*}$ & June & May-July \\
\hline Females & 163 & 1.26 & $1-1.96$ & 0.58 & May & February-September \\
\hline By hanging & 319 & 1.63 & $1-2.10$ & $0.009 *$ & May & April-June (late) \\
\hline By jumping & 298 & 1.45 & $1-2.00$ & 0.08 & July (late) & June (early)-September \\
\hline By shooting & 146 & 1.68 & $1-2.67$ & 0.09 & May & March (late)-July \\
\hline Age $<45$ & 340 & 1.25 & $1-1.59$ & 0.35 & May & March-August \\
\hline Age $\geq 45$ & 525 & 1.60 & $1.25-2.04$ & $0.001^{*}$ & June & May-July \\
\hline
\end{tabular}

*statistically significant; Missing observations for age: two in 2008-2010, one in 2011-2012 and three in 2008-2012. RR: relative risk, CI: confidence interval 
cide by hanging with a peak early in the month of June $(\mathrm{p}=0.03)$ and an increased suicide risk of $96 \%$, whereas no other method demonstrated significant seasonal variation (Table 2).

\section{DISCUSSION}

This study aimed to investigate the possible effect of the economic crisis on the seasonality of suicides in the Athens Greater Area. The economic crisis and the following implementation of austerity measures in Greece in the middle of 2010 lead to significant increase of unemployment, drop in income, inability to repay debts and closure of many businesses. The effects of the crisis were felt by the Greek population during the years 2011 and 2012.89 To the best of our knowledge this is the first study to investigate the impact of Greece's economic crisis on suicide seasonality, as well as one of the few internationally that examines seasonal variation during an economic crisis period. According to our study the seasonality of suicides was confirmed for the total suicide cases examined. Suicide seasonality was present during 2008-2010 and strengthened significantly in 2011-2012. More analytically, regarding the period 2008-2010, significant seasonality was established for the individuals aged 45 years or more, while concerning the period 2011-2012, significant seasonality was observed for males, for individuals aged 45 years or more and for suicide by hanging.

Madianos et al. ${ }^{12}$ reported that suicide mortality rates were increased by $55.8 \%$ between 2007 and 2011, when the austerity measures were implemented, while the total mortality was increased by only $1.1 \%$. Similar results were reported by Rachiotis et al. ${ }^{13}$ who found that the suicide rates overall increased by 35\% between 2010 and 2012. As shown in Figure 1, an increasing tendency of suicide rates in Greece has been found. These results coincide with the findings of recent general population surveys in Greece nationwide, that indicated a substantial increase in the prevalence of suicidal ideation and reported suicide attempts between 2008 and 2011. ${ }^{9}$ Other studies have also documented that the number of suicides increased during periods of economic changes compared to those of economic stability. ${ }^{14,15}$

Only a few studies internationally have examined the seasonal variation of suicides during times of economic crisis or economic transition. Although those studies agree that suicide seasonality is established and remains significant, they either support that it has diminished ${ }^{4,5}$ or it has strengthened especially in suicides by hanging. ${ }^{16}$

In the present study, the seasonal variation of deaths by suicide appeared significant during the period from 2008 to 2010 and strengthened during the period from 2011 to 2012, when the impact of the austerity measures was increasingly being felt by the Greek society. The results are perfectly com- parable with those of our previous study concerning a five-year period from 1996 to 2000, when there was no apparent economic crisis, while the data of that study were also collected from the Athens Department of Forensic Medicine. ${ }^{7}$ In that study, a seasonal variation with a peak in late spring-early summer was also established, by using the Frangakis and Varadhan method. ${ }^{11}$ It concerned mainly men, individuals aged 45 years or more, and suicides by shooting and hanging.

In comparison with the results of that study, it appears that during the time period between 2011 and 2012, as far as the overall seasonality is concerned the RR increased from 1.32 to 1.69 and the statistical significance from $\mathrm{p}=0.02$ to $\mathrm{p}=$ 0.002 . Moreover, regarding men, $\mathrm{RR}$ increased from 1.41 to 1.75 and the statistical significance from $\mathrm{p}=0.01$ to $\mathrm{p}=0.005$. Concerning suicides by hanging, RR increased from 1.52 to 1.96 with a stable statistical significance $(\mathrm{p}=0.03)$. Finally, regarding the individuals aged 45 years or more the RR increased from 1.40 to 1.75 and the significance from $\mathrm{p}=0.05$ to $\mathrm{p}=0.027$.

The findings of the current study did not confirm our initial hypothesis, which was that suicide seasonality should diminish significantly or even disappear due to the acute and continuous deterioration of the economic situation, which should reasonably outweigh the other factors that contribute to seasonality. It may be suggested that this socio-economic situation worsens other factors related to the seasonality of suicide. We could assume some "aspects of anomie" as described by Durkheim ${ }^{17}$ that appear in societies where disasters and transition from one state to another take place and which could have an impact on the seasonal pattern of suicide. "Broken hope" and "failed promise" may have increased the risk of suicide; frustration resulting from such broken promises might also explain any rise of suicide in the freshness of spring. ${ }^{18}$ These along with the timing of the economic crisis, as well as with poverty which

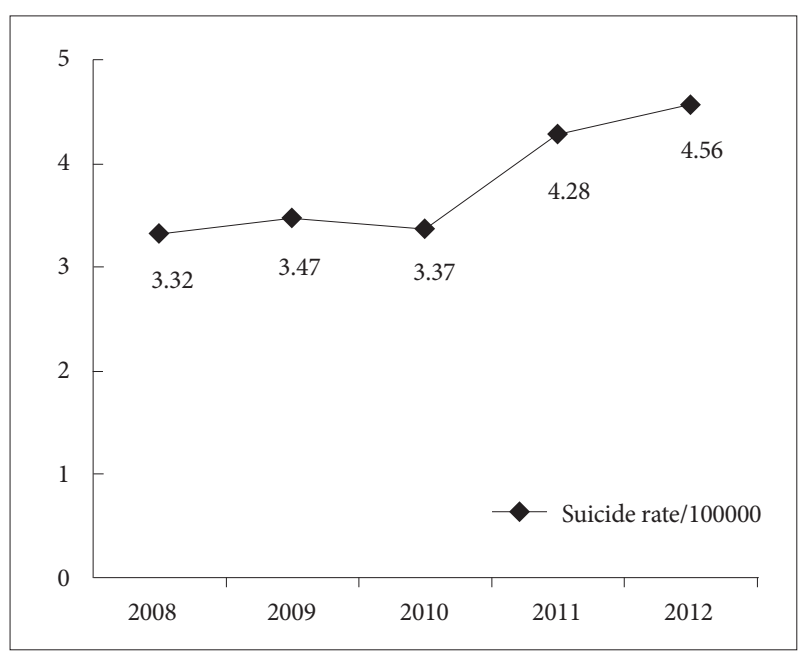

Figure 1. Annual suicide rates in Greece from 2008 to 2012. 
increases the propensity of suicide by means of the association with suicidogenic conditions, such as unemployment, financial stress, family instability, and mental troubles (e.g., depression, poor physical health, alcoholism), ${ }^{19}$ might preserve the overall effect of seasonality in incidence of suicide.

Some limitations of our study should be mentioned. The study reports mainly suicides that have occurred in the Athens Greater Area (Prefecture of Attica). Although the latter is the largest urban area of the country and has almost half of the total Greek population, our study should not be considered as nationwide. The time period examined (five years) was rather small. However, it should be noted that our purpose was to study the suicide seasonality mainly during the crisis period. Finally, the recognition of all the suicide cases was based on autopsy examination and the incorporation of data as reported to the referral for autopsy medical summaries, and thus the results should be viewed with relative caution.

In conclusion, it seems that the economic crisis in Greece, especially in the period during its effects had an impact on the economic condition of the citizens with devastating consequences for a significant number of the population, strengthened the seasonality of suicides, while a noteworthy suicide risk of $96 \%$ was revealed for suicides by hanging (peak in early June).

\section{REFERENCES}

1. Christodoulou C, Douzenis A, Papadopoulos FC, Papadopoulou A, Bouras G, Gournellis R, et al. Suicide and seasonality. Acta Psychiatr Scand 2012;125:127-146.

2. Ajdacic-Gross V, Bopp M, Ring M, Gutzwiller F, Rossler W. Seasonality in suicide-a review and search of new concepts for explaining the heterogeneous phenomena. Soc Sci Med 2010;71:657-666.

3. Stack S. Suicide: a 15-year review of the sociological literature. Part I: cultural and economic factors. Suicide Life Threat Behav 2000;30:145-162.
4. Kalediene R, Starkuviene S, Petrauskiene J. Seasonal patterns of suicides over the period of socio-economic transition in Lithuania. BMC Public Health 2006;6:40.

5. Araki S, Murata K. Suicide in Japan: socioeconomic effects on its secular and seasonal trends. Suicide Life Threat Behav 1987;17:64-71.

6. Bazas T, Jemos J, Stefanis K, Trichopoulos D. Incidence and seasonal variation of suicide mortality in Greece. Compr Psychiatry 1979;20:1520.

7. Christodoulou C, Papadopoulos IN, Douzenis A, Kanakaris N, Leukidis C, Gournellis R, et al. Seasonality of violent suicides in the Athens greater area. Suicide Life Threat Behav 2009;39:321-331.

8. Kentikelenis A, Karanikolos M, Reeves A, McKee M, Stuckler D. Greece’s health crisis: from austerity to denialism. Lancet 2014;383:748-753.

9. Economou M, Madianos M, Peppou LE, Theleritis C, Patelakis A, Stefanis C. Suicidal ideation and reported suicide attempts in Greece during the economic crisis. World Psychiatry 2013;12:53-59.

10. Kontaxakis V, Papaslanis T, Havaki-Kontaxaki B, Tsouvelas G, Giotakos O, Papadimitriou G. Suicide in Greece: 2001-2011. Psychiatriki 2013; 24:170-174.

11. Frangakis CE, Varadhan R. Confidence intervals for seasonal relative risk with null boundary values. Epidemiology 2002;13:734-737.

12. Madianos MG, Alexiou T, Patelakis A, Economou M. Suicide, unemployment and other socioeconomic factors: evidence from the economic crisis in Greece. Eur J Psychiatry 2014;28:39-49.

13. Rachiotis G, Stuckler D, McKee M, Hadjichristodoulou C. What has happened to suicides during the Greek economic crisis? Findings from an ecological study of suicides and their determinants (2003-2012). BMJ Open 2015;5:e007295.

14. Araki S, Murata K. Suicide mortality in Japan: analysis of the unusual secular trends. Tohoku J Exp Med 1986;149:205-211.

15. Tamosiunas A, Reklaitiene R, Virviciute D, Sopagiene D. Trends in suicide in a Lithuanian urban population over the period 1984-2003. BMC Public Health 2006;6:184.

16. Voracek M, Vintila M, Fisher ML, Yip PS. Evidence for lack of change in seasonality of suicide from Timis County, Romania. Percept Mot Skills 2002;94:1071-1078.

17. Durkheim E. Suicide. Free Press: New York; 1966.

18. Gabennesch $\mathrm{H}$. When promises fail: a theory temporal fluctuations in suicide. Soc Forces 1988;67:129-145.

19. Stack S. Suicide: a decade review of sociological literature. Deviant Behav 1982;4:41-66. 